http://dx.doi.org/10.4314/ejotmas.v7i1-2.1

\title{
Editorial
}

\section{EJOTMAS: RAISING THE RESEARCH AND PUBLICATION BAR AT AMBROSE ALLI UNIVERSITY, EKPOMA, NIGERIA}

It is with great excitement, enthusiasm and trepidation that we announce the release of volume 7, numbers 1 and 2 of EJOTMAS: Ekpoma Journal of Theatre and Media Arts. All three feelings grew out of the fact that we have been working strenuously to raise the bar as far as the quality, reputation, circulation and indexation of the biennial output of the journal is concerned. Not unmindful of the structural challenges that impinge on intellectual work or knowledge production in Africa, we have gradually built capacities in the areas of plagiarism checks, acquisition of digital object identifiers (DOIs), strong web presence, wide readership, among others, through partnerships with organisations such as the African Journals Online (AJOL), UlrichsWeb, MLA Bibliography International, Society of African Journal Editors (SAJE), and the Ambrose Alli University ICT Unit (AAU Online). That is, aside the AAU Online where we are listed, EJOTMAS is now listed in MLA International Bibliography, UlrichsWeb, AJOL, SAJE, WorldCat, etc. This is a milestone that is worth noting even at the level of Ambrose Alli University, Ekpoma that is determined to be a leading university in Nigeria and beyond. Following the recent publication of the Times Higher Education University Rankings standards, universities are now generally assessed on 5 pillars, namely, Teaching, Research, Citations, Industry Income and Internationalisation (par 4). We are proud to announce that this development has been the driving force behind EJOTMAS, and its parent university, Ambrose Alli University, Ekpoma.

EJOTMAS was established in 2004 and in the last 15 years SONTA laureates and award winners, Ahmed Yerima, Israel Wekpe, and Saviour Nathan Agoro have published with us. Later, Marcel Okhakhu, Bibian Anyanwu, Vasudeva Swami, Charles Aluede, Barth Oshionebo, AbdulRasheed Adeoye, Mariam Asabe Iyeh, Ruth OliseEpochie, have featured among other notable scholars. It has developed a standard practice of peer-review because we recognise the indispensability and imperativeness of peer-review in successful journal production. All papers submitted to it are subjected to the rigours that a refereed journal should go through. Its structured guidelines are in line with scientific publishing practices. The journal's robust doubleblind peer-review process guarantees quality. Clark, Liebenberg and Sousa assert that the quality of a review rests on the expertise and thoughtfulness of many individuals whose efforts in doing timely and 
complete reviews are seldom recognized and celebrated sufficiently (1). At EJOTMAS, we endeavour to select reviewers well matched to our submissions and experienced in their subfields of theatre and media arts studies. While many reviewers report that they find reviewing personally rewarding and informative, others find this act of sacrificing time and expertise under-appreciated. In this regard, we wish to thank our reviewers: those we pay honoraria and those that offer their invaluable services pro bono, for their immeasurable sacrifice for the greater promotion of scholarship.

Recognizing this debt to this journal, we devote this editorial to pay tribute to our wonderful reviewers - without whose contributions, there would be no peer-reviewed journal and both our work and our methods would be ineffectual. This is the point Clark, Liebenberg and Sousa eloquently made and rightly so too, when they said, if one tries to get anything meaningfully done around research, one will quickly run into the imperative of interacting and working with others. No team does research on its own anymore (1-2). This is quite edifying as our journal is a product of team work in and outside the Department of Theatre and Media Arts, Ambrose Alli University, Ekpoma with our ever growing number of readers and contributors, reviewers and indexers across the world. Without all these persons, EJOTMAS will be nowhere. We say a big thank you to all.

At present, EJOTMAS remains the only journal in Ambrose Alli University, Ekpoma that has been listed / indexed by at least four world class indexation bodies. We believe that by the foundation we have laid, the journal will only grow from strength to strength in terms of open access format. This, assuredly, will lead to broader readership, increased downloads, and potentially increased citations, interdisciplinary and trans-disciplinary outlook, abstracting, which are hallmarks of research and publication in the 21st century global research community.

In this volume 7, numbers 1 and 2, we have 32 illuminating articles spread across virtually all the subfields of theatre and media arts studies and some aspects of humanistic sciences. We hope as you go through them you will be stimulated, if not provoked intellectually to take your research to the next level. We thank all the contributors once again for their patience, cooperation and understanding while the preparation of the volume lasted. Also, we thank them for the insights and interesting perspectives they canvassed in their very fascinating studies. As we look up to the future with hope, we call on all well-meaning individuals and corporate bodies to join us by way of sponsorship because of the prohibitive cost of producing a high quality journal such as EJOTMAS. We will appreciate if bodies can pick advert 
spaces with us as our journal is capable of giving mileage to their products and services.

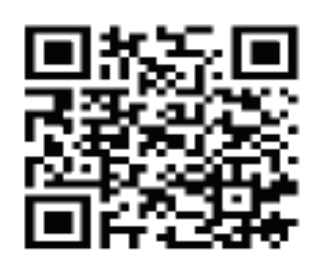

Osakue Stevenson OMOERA, Ph.D., FIMIM, M.Sonta

Editor

\section{Works Cited}

Clark, Alexander M., Linda Liebenberg and Bailey J. Sousa. "The Indispensability and Imperative of Peer Review: Heartfelt Thanks." International Journal of Qualitative Methods 17(2018): 1-3. DOI: 10.1177/1609406918767669.

The Times Higher Education World University Rankings 2020. Web. 2 August 2019. <https://www.timeshighereducation.com/worlduniversity-rankings/2020/world-ranking\#!/page/O/length/25/ sort_by/rank/sort_order/asc/cols/stats>. 